\title{
Variabilidade espacial de atributos físicos e mecânicos de um Argissolo sob cultivo de cana-de-açúcar ${ }^{1}$
}

\author{
U ilka E. Tavares'2, Mario M. Rolim², Elvira M. R. Pedrosa², \\ Abelardo A. A. Montenegro ${ }^{2}$, Adriana G. Magalhães ${ }^{2} \&$ Marcela T. L. Barreto $^{3}$
}

RESU M 0

Propôs-se, neste trabalho, estudar a relação espacial de atributos físicos e mecânicos de um Argissolo Coeso cultivado com cana-de-açúcar. Estabeleceu-se um grid com 49 pontos georreferenciados para a retirada de amostras, em disposição $7 \times 7$, resultando uma malha de $120 \times 120 \mathrm{~m}$. As trincheiras foram abertas em duas camadas $(0-20$ e $20-40 \mathrm{~cm})$ para a coleta das amostras deformadas e indeformadas. A distribuição normal foi verificada em todas as variáveis estudadas. Também se observou forte grau de dependência espacial para a maioria das variáveis. O limite de plasticidade apresentou efeito pepita puro. 0 s maiores alcances encontrados foram para o limite de liquidez $(0-20 \mathrm{~cm})$ e grau de compactação $(0-20 \mathrm{~cm})$ e os menores para umidade do solo $(0-20 \mathrm{~cm})$, IP e carbono orgânico $(20-40 \mathrm{~cm})$. O s mapas de krigagem apontaram correlação inversa entre densidade e porosidade e forte correlação entre argila e carbono orgânico, também entre a argila e os limites de consistência. Para a maioria das variáveis houve dependência espacial até $20 \mathrm{~m}$ indicando, para análises paramétricas, que as amostras devem ser coletadas em distâncias superiores a $20 \mathrm{~m}$.

Palavras-chave: proctor, limites de consistência, dependência espacial

\section{Spatial variability of physical and mechanical attributes of an Ultisol under sugarcane crop}

\begin{abstract}
A B ST RAC T
The purpose of this study was to evaluate the spatial relation of physical and mechanical attributes of a cohesive UItisol cultivated with sugarcane. Forty nine georeferenced points were established for the collection of samples, with $7 \times 7$ grid, forming a mesh of $120 \times 120 \mathrm{~m}$. The trenches were opened at two layers $(0-20$ and $20-40 \mathrm{~cm})$ for the collection of disturbed and undisturbed samples. The normal distribution was observed in all variables. Strong degree of spatial dependence was also observed for most variables. The plastic limit show ed nugget effect. The highest range was found for the liquid limit $(0-20 \mathrm{~cm})$ compaction degree $(0-20 \mathrm{~cm})$ and lowest for soil moisture $(0-20 \mathrm{~cm})$, IP and organic carbon $(20-40 \mathrm{~cm})$. Kriging maps showed an inverse correlation between density and porosity and strong correlation between clay and organic carbon as well as between the clay and the limits of consistence. For most variables, there was spatial dependence up to $20 \mathrm{~m}$, indicating that for parametric analysis, samples should be collected at distances over $20 \mathrm{~m}$.
\end{abstract}

Key words: proctor, consistence limits, spatial dependence

\footnotetext{
${ }^{1}$ Parte da Dissertação de Mestrado do primeiro autor apresentada ao Programa de Pós-Graduação em Engenharia Agrícola da UFRPE, com bolsa da CAPES

2 DTR/U FRPE, Rua D om Manoel de Medeiros s/n, D ois Irmãos, CEP 52171-900, Recife, PE. Fone: (81) 3320-6279. E-mail: uetavares@yahoo.com.br; rolim@dtr.ufrpe.br; elvira.pedrosa@dtr.ufrpe.br; abelardo.montenegro@yahoo.com.br; agmguedes@gmail.com;

3 IFPE/E-Tec, Av. Prof Luiz Freire, 500 Cidade U niversitária - Recife/PE - CEP: 50740-540, Recife, PE. E-mail: marcelatlb@gmail.com
} 


\section{INTRODUÇÃO}

A produção brasileira de cana-de-açúcar para a safra 2011/ 2012 foi de $571.439,3 \mathrm{t}$, sendo $70.059,0 \mathrm{t}$ a parcela de produção referente ao Norte e Nordeste; deste total, o Estado de Pernambuco é o segundo maior produtor contribuindo com $27,3 \%$ da produção da região (CONAB, 2012). Em 2009 a canade-açúcar atingiu a maior participação na matriz energética brasileira desde o início do levantamento, em 1992. Dada a sua importância econômica, a cana-de-açúcar é considerada, atualmente, uma commodity (Farias et al., 2009) valorizada pelo potencial de gerar energia limpa e renovável e de substituir parte da matriz energética global centrada, hoje, na utilização de combustíveis hidrocarbonetos de origem fóssil.

Uma parcela das áreas cultivadas com cana-de-açúcar em Pernambuco é de tabuleiros costeiros. Nessas regiões alguns dos solos podem ser classificados coesos em virtude das condições climáticas e do relevo constituído pelo Grupo Barreiras, que favorece a formação dos horizontes coesos. Os horizontes coesos apresentam consistência dura a muito dura, quando secos e friável quando úmidos embora todos os solos da região de tabuleiros possuam fortes limitações agrícolas por apresentarem baixa fertilidade e baixa reserva de nutrientes.

Além das propriedades intrínsecas desses solos, a mecanização do seu preparo por meio de tratores e subsoladores, tal como na colheita na maioria das vezes em condições inadequadas de umidade, pode influenciar negativamente a qualidade do solo causando o aumento da sua densidade, a aproximação das partículas sólidas entre si e redução da macroporosidade (Severiano et al., 2010) praticamente sem alterar a microporosidade (Dias Júnior \& Pierce, 1996) levando o solo a apresentar problemas de compactação.

Desta forma, a susceptibilidade do solo à compactação é função da estrutura física e das características químicas as quais, por sua vez, podem ser influenciadas pela presença de matéria orgânica (Braida et al., 2010). A redução da matéria orgânica do solo em razão do cultivo pode reduzir a umidade ótima de compactação aumentando, assim, os riscos à compactação visto que os solos podem atingir a compactação máxima, mesmo quando trabalhados na condição de baixos teores de umidade do solo (Silva et al., 2006a). Silva et al. (2006b) observaram, em pesquisa realizada sobre a ação da matéria orgânica nas propriedades físicas de um Argissolo Amarelo coeso, redução nos teores de carbono orgânico total e a matéria orgânica, em virtude do cultivo da cana-de-açúcar e posterior queimada da cana antes da colheita, em comparação com a área de mata nativa e, ainda, que os sistemas de sequeiro e irrigado apresentaram menores valores de umidade ótima de compactação.

A matéria orgânica é passível, ainda, de aumentar a faixa de friabilidade do solo, istoé, a faixa que compreende o limite de contração e plasticidade, que corresponde à umidade ideal para o preparo do solo (Silva et al., 2006b). Alterações nos limites de consistência do solo em razão das modificações nos teores de carbono orgânico também foram observadas por outros autores (Oliveira et al., 2010a; Vasconcelos et al., 2010), ao constatarem que o aumento da matéria orgânica tende a aumentar a área superficial específica do solo, o que proporciona maior retenção de água, levando-o a ter maiores valores para os limites de plasticidade do solo. Assim, os solos cultivados podem ter sua faixa de friabilidade reduzida devido à baixa na concentração de matéria orgânica, contribuindo para o aumento da compactação.

Ficou patente que, pela adição de resíduos orgânicos da cana-de-açúcar, o aumento do teor de matéria orgânica proporcionou uma degradação menor dos atributos físicos e químicos do solo, provocando elevação dos limites de consistência do solo e redução do risco de deformação plástica, de um Latossolo Amarelo distrocoeso sob aplicação de diferentes resíduos da cana-de-açúcar (Vasconcelos et al., 2010).

Assim, Miranda et al. (2007) sugerem, após estudarem a compactação do solo em área de cana-de-açúcar, que se realize um levantamento completo das propriedades e características desse solo e que, através do uso da geoestatística, sua variabilidade espacial seja estimada, quantificando a dependência espacial entre o campo e as amostras para se obter mapas de tráfego agrícola em função das variáveis estudadas. Tais estudos são essenciais para o desenvolvimento de planos de amostragem com vistas à aplicação em programas de manejo integrado.

Desta forma, o presente trabalho objetivou estudar a relação espacial de atributos físicos e mecânicos de um Argissolo Coeso cultivado com cana-de-açúcar e suas inter-relações em tabuleiro costeiro do Estado de Pernambuco.

\section{Material e MÉTODOS}

O experimento foi realizado em um Argissolo Coeso situado na Usina Santa Tereza, Goiana, PE, localizada na mesorregião mata e na microrregião mata Setentrional do Estado de Pernambuco, próximo às coordenadas $7^{\circ} 33^{\prime} 38$ de latitude sul e $35^{\circ} 00^{\prime} 09$ de longitude oeste, distando $65,7 \mathrm{~km}$ da cidade de Recife. Segundo a classificação climática de Köppen-Geiger, a área é tropical úmida do tipo As' ou pseudotropical, que se caracteriza por ser quente e úmida, com chuvas de outono a inverno, com temperaturas médias anuais variando em torno de $24^{\circ} \mathrm{C}$.

A cana-de-açúcar cultivada na área é da variedade RB 92579, que vem sendo fertirrigada com 2 lâminas de $60 \mathrm{~mm}$ de vinhaça, há 7 anos. Segundo Bebé et al. (2009), nas áreas de Argissolos da usina os teores de sódio apresentaram média de 0,32 $\mathrm{cmol}_{\mathrm{c}} \mathrm{dm}^{-3}(0,00-0,20 \mathrm{~m})$ e $0,29 \mathrm{cmol}_{\mathrm{c}} \mathrm{dm}^{-3}(0,20-0,40 \mathrm{~m})$ e de potássio de $0,36 \mathrm{cmol}_{c} \mathrm{dm}^{-3}(0,00-0,20 \mathrm{~m})$ e $0,18 \mathrm{cmol}_{c} \mathrm{dm}^{-3}(0,20-$ $0,40 \mathrm{~m})$. O corte é feito manualmente e o manejo do solo é o convencional com emprego de grade pesada e média, além de subsolador e sulcador.

Coletaram-se 49 amostras deformadas de solo, para análise de textura, densidade das partículas, densidade seca máxima e umidade crítica, obtidas pelo ensaio normal de Proctor, limites de consistência e carbono orgânico além de 49 amostras indeformadas com vista à avaliação da densidade do solo, umidade gravimétrica, em locações distantes $20 \mathrm{~m}$ entre si, em uma malha quadrada, nas camadas 0-20 e 20-40 cm. 
As coletas foram realizadas no período de maio a novembro de 2010, nos dias de menor pluviosidade. O corte da cana na área escolhida ocorreu no mês de dezembro de 2010.

A densidade do solo (Ds) foi determinada pela relação entre o peso do solo secado em estufa e o volume do anel usado no amostrador de Uhland, a umidade gravimétrica (Ug) obtida pela relação entra a massa de água existente no solo e a massa seca (EMBRAPA, 1997). Determinou-se a densidade das partículas através do balão volumétrico de $50 \mathrm{~mL}$, utilizando a terra fina secada na estufa (TFSE) a $105^{\circ} \mathrm{C}$ e álcool etílico absoluto cujos resultados foram expressos em $\mathrm{g} \mathrm{m}^{-3}$ de volume das partículas. A porosidade total $(\mathrm{Pt})$ foi calculada a partir dos valores da densidade do solo e densidade das partículas expressa em percentagem, segundo EMBRAPA(1997).

A granulometria foi determinada através do método do densímetro de Boyoucos em que se utilizou, como dispersante, a solução de calgon (hexametafosfato de sódio). Foram realizadas as determinações quantitativas das frações de argila $(<0,002 \mathrm{~mm})$, silte $(0,002-0,05 \mathrm{~mm})$ e areia $(0,05-0,20 \mathrm{~mm})$, expressas em $\mathrm{g} \mathrm{kg}^{-1}$ enquanto o carbono orgânico (CO) foi determinado via úmida com dicromato de potássio em meio sulfúrico(EMBRAPA, 1997).

O ensaio normal de Proctor foi realizado através de um cilindro de Proctor para obtenção da densidade seca máxima de compactação $\left(\mathrm{D}_{\text {smax }}\right)$ e da umidade crítica (Ucrit) (Oliveira et al., 2010b).

O limite de liquidez (LL) e o limite de plasticidade (LP) foram determinados, respectivamente, conforme Vasconcelos et al. (2010) e o índice de plasticidade (IP) obtido pela sua diferença. O grau de compactação (GC) foi definido pela relação entre a densidade do solo (Ds) e a densidade seca máxima de compactação $\left(\mathrm{D}_{\mathrm{smax}}\right)$, obtida pelo ensaio normal de Proctor (Oliveira et al., 2010b). Com os dados obtidos foram efetuados a estatística descritiva dos dados e o estudo de correlações simples entre algumas variáveis, utilizando-se o software Statistica (Statsoft, 2004).
A hipótese de normalidade foi avaliada pelo teste de Kolmogorov-Smirnov, por meio de planilha eletrônica Excel. O critério de Hoaglin (Hoaglin et al., 1992) foi aplicado para remoção de valores discrepantes que, na maioria das vezes, são indicativos de erro na leitura das variáveis (Guimarães et al., 2010).

O grau de variabilidade foi estimado pelo coeficiente de variação $(\mathrm{CV})$ dos atributos, conforme sugerido por Warrick \& Nielsen (1980) que consideram baixa variabilidade quando CV $<12 \%$; média para o intervalo $12-60 \%$ e alta variabilidade quando $\mathrm{CV}>60 \%$.

A dependência espacial foi avaliada por meio de ajuste de semivariograma, com base na pressuposição de estacionaridade da hipótese intrínseca, por meio do programa Geoeas (Englund \& Sparks, 1991). Para os modelos de semivariogramas que não apresentaram estacionaridade, foi retirada a tendência. Os modelos ajustados foram validados utilizando-se a técnica geoestatística de Jack-Knifing. Para a confecção dos mapas espaciais utilizou-se o software Surfer 7.0 (Golden Software, 1999).

A análise do grau de dependência espacial (GDE) foi realizada segundo Cambardella et al. (1994) que preconizam a proporção em porcentagem do efeito pepita $\left(\mathrm{C}_{0}\right)$ em relação ao patamar $\left(\mathrm{C}_{0}+\mathrm{C}_{1}\right)$ e apresentam: (a) dependência forte $<25 \%$; (b) dependência moderada entre 25 e $75 \%$ e (c) dependência fraca $>75 \%$.

\section{RESULTADOS E DISCUSSÃO}

A análise dos dados mostrou que os coeficientes de assimetria e curtose estão próximos de zero sinal de que as variáveis apresentam distribuição próxima à Normal (Tabela 1). As variáveis analisadas indicaram baixo valor de $\mathrm{CV}$, com exceção do silte e do carbono, nas duas camadas investigadas, segundo o critério de Warrick \& Nielsen (1980).

Tabela 1. M edidas descritivas dos dados de densidade $\left(\mathrm{g} \mathrm{cm}^{-3}\right)$, umidade do solo (\%), porosidade total (\%), areia, silte e argila $\left(\mathrm{g} \mathrm{kg}^{-1}\right)$, carbono orgânico $\left(\mathrm{g} \mathrm{kg}^{-1}\right)$, densidade seca máxima $\left(\mathrm{g} \mathrm{cm}^{-3}\right)$, umidade crítica $(\%)$, limite de liquidez, limite de plasticidade e índice de plasticidade (em \%) e grau de compactação (\%)

\begin{tabular}{|c|c|c|c|c|c|c|c|c|c|c|c|c|c|}
\hline Parâmetros & ${ }^{1}$ Ds & ${ }^{2} U g$ & ${ }^{3} \mathrm{Pt}$ & ${ }^{4} \mathrm{LL}$ & ${ }^{5} \mathrm{LP}$ & ${ }^{6} \mathrm{IP}$ & ${ }^{7}$ Dsmax & ${ }^{8}$ Ugcrit & ${ }^{9} \mathrm{GC}$ & ${ }^{10} \mathrm{CO}$ & Areia & Silte & Argila \\
\hline \multicolumn{14}{|c|}{$0-20 \mathrm{~cm}$} \\
\hline Média & 1,47 & 13,42 & 47,43 & 25,88 & 21,84 & 4,06 & 1,75 & 14,77 & 83,78 & 20,33 & 587,77 & 60,68 & 351,55 \\
\hline Mediana & 1,49 & 13,42 & 47,67 & 26,00 & 22,00 & 4,00 & 1,75 & 14,76 & 83,70 & 20,24 & 580,20 & 62,00 & 353,20 \\
\hline${ }^{11} \mathrm{DP}$ & 0,16 & 2,25 & 5,27 & 0,53 & 0,37 & 0,47 & 0,03 & 1,50 & 8,78 & 8,14 & 50,07 & 35,81 & 48,39 \\
\hline Curtose & 0,20 & 0,11 & $-0,67$ & 22,02 & 1,60 & 7,95 & $-0,51$ & $-0,40$ & $-0,07$ & $-0,33$ & 0,02 & 0,94 & $-0,58$ \\
\hline Assimetria & 0,23 & 0,03 & $-0,07$ & $-4,64$ & $-1,88$ & $-1,01$ & 0,35 & $-0,19$ & 0,25 & 0,67 & 0,64 & 0,76 & 0,34 \\
\hline Mínimo & 1,35 & 11,82 & 43,39 & 26,00 & 22,00 & 4,00 & 1,73 & 13,97 & 76,38 & 13,35 & 548,40 & 35,16 & 316,00 \\
\hline Máximo & 1,56 & 14,82 & 51,66 & 26,00 & 22,00 & 4,00 & 1,77 & 15,72 & 89,43 & 25,67 & 625,20 & 85,64 & 383,20 \\
\hline${ }^{12} \mathrm{CV}$ & 0,11 & 0,17 & 0,11 & 0,02 & 0,02 & 0,12 & 0,02 & 0,10 & 0,10 & 0,40 & 0,09 & 0,59 & 0,14 \\
\hline \multicolumn{14}{|c|}{$20-40 \mathrm{~cm}$} \\
\hline Média & 1,54 & 13,86 & 45,27 & 26,06 & 21,88 & 4,20 & 1,74 & 15,64 & 88,08 & 13,87 & 571,84 & 58,93 & 363,45 \\
\hline Mediana & 1,54 & 13,88 & 44,89 & 26,00 & 22,00 & 4,00 & 1,74 & 15,68 & 87,73 & 14,17 & 555,60 & 59,20 & 364,28 \\
\hline${ }^{11} \mathrm{DP}$ & 0,15 & 2,48 & 4,44 & 0,32 & 0,39 & 0,54 & 0,04 & 1,27 & 8,83 & 3,30 & 57,74 & 30,19 & 44,23 \\
\hline Curtose & 0,01 & $-0,51$ & $-0,22$ & 31,76 & 2,73 & 4,00 & $-0,69$ & 0,16 & $-0,06$ & $-0,82$ & $-0,57$ & $-0,65$ & $-0,41$ \\
\hline Assimetria & $-0,19$ & 0,22 & 0,15 & 5,54 & $-1,20$ & 1,81 & 0,74 & $-0,91$ & $-0,04$ & $-0,19$ & 0,27 & $-0,04$ & 0,02 \\
\hline Mínimo & 1,46 & 11,93 & 42,32 & 26,00 & 22,00 & 4,00 & 1,72 & 15,26 & 84,09 & 11,36 & 531,00 & 37,20 & 332,12 \\
\hline Máximo & 1,65 & 15,57 & 47,99 & 26,00 & 22,00 & 4,00 & 1,77 & 16,85 & 94,15 & 16,27 & 617,50 & 80,24 & 393,48 \\
\hline${ }^{12} \mathrm{CV}$ & 0,09 & 0,18 & 0,10 & 0,01 & 0,02 & 0,13 & 0,02 & 0,08 & 0,10 & 0,24 & 0,10 & 0,51 & 0,12 \\
\hline
\end{tabular}

${ }^{1}$ Densidade do solo; ${ }^{2}$ teor de água; ${ }^{3}$ porosidade total ${ }^{4}$ limite de liquidez; ${ }^{5}$ limite de plasticidade; ${ }^{6}$ índice de plasticidade; ${ }^{7}$ densidade seca máxima; ${ }^{8}$ umidade crítica; ${ }^{9}$ grau de compactação; ${ }^{10}$ carbono orgânico; ${ }^{11}$ desvio padrão; ${ }^{12}$ coeficiente de variação 
Verifica-se, na Tabela 1, que as médias da densidade do solo, umidade, argila, umidade crítica, os limites de consistência e GC sinalizaram maiores valores na camada de $20-40 \mathrm{~cm}$, indicando que o GC pode estar sendo influenciado especificamente por essas variáveis.

Pela observação das médias é possível constatar que os limites de consistência aumentaram com a profundidade, o que também foi verificado por Vasconcelos et al. (2010) devido, sem dúvida, ao aumento do teor de argila no solo (Tabela 1) compensando, de certo modo, a redução da matéria orgânica com o aumento da profundidade.

A média da umidade crítica (Ugcrit) de compactação foi menor que o valor do LP, fato também constatado por Figueiredo et al. (2000) que, estudando um Latossolo Roxo localizado no Campus da Universidade Federal de Lavras, MG, sugerem que se evite trafegar com máquinas quando a umidade do solo for aproximadamente igual ao limite de plasticidade, visto que a Ugcrit está contida na faixa de umidade em que o tráfego de máquinas é realizado.

Figueiredo et al. (2000) observaram que a umidade do solo que afeta os trabalhos com máquinas agrícolas está próxima a $90 \%$ do limite de plasticidade. Com relação aos valores da Ugcrit nas duas camadas, verifica-se que estão pouco abaixo dos valores de umidade igual a $90 \%$ do limite de plasticidade $(19,65$ e $19,68 \%$, respectivamente).

O carbono orgânico $(\mathrm{CO})$ apresentou maior valor médio na camada 0-20 cm do solo e diminuiu com o aumento da camada; tal comportamento foi devido à deposição de resíduos vegetais na superfície do solo.

Segundo Bonini et al. (2011) a densidade do solo é uma das propriedades físicas que podem caracterizar o estado de compactação. Os valores encontrados (Tabela 1) se apresentam na faixa de 1,47 e $1,54 \mathrm{~kg} \mathrm{dm}^{-3}$ para as camadas de 0-20 e 20-40 $\mathrm{cm}$, respectivamente; os valores podem ser considerados altos. Klein (2006) constatou que valores a partir de $1,33 \mathrm{~kg} \mathrm{dm}^{-3}$ são limitantes ao crescimento radicular, porém Siqueira et al. (2008) apontam que não há um consenso quanto ao valor crítico da densidade do solo.

O maior teor de areia foi encontrado na camada $0-20 \mathrm{~cm}$ do solo visto que as areias tendem a alcançar maiores valores de densidade máxima $\left(\mathrm{Ds}_{\max }\right)$ pelo ensaio de Proctor normal e a diferença entre a $\mathrm{Ds}_{\max }$ nas duas camadas foi pequena (Tabela 1) fato atribuído, provavelmente, à influência do $\mathrm{CO}$ e do teor de argila.

Ocorreu modificação textural do solo pela mobilidade da argila para a camada $20-40 \mathrm{~cm}$ o que, segundo Silva \& Cabeda (2006) pode ser causado por processos naturais provocando o adensamento desta faixa e em virtude, também, da ação antrópica na área; esses autores afirmam, ainda, estudando um Argissolo Amarelo coeso cultivado com cana-de-açúcar, que o cultivo da cana pode alterar a organização da matriz do solo promovendo um arranjo mais compacto em áreas cultivadas sob sequeiro, irrigado e vinhaça, em relação à área de mata.

As médias do limite de liquidez e do teor de argila aumentaram com a profundidade do solo. Kondo \& Dias Junior (1999) afirmam que maiores teores de argila tendem a aumentar os valores de limites de liquidez (LL) e plasticidade (LP), proporcionados pelo aumento da capacidade de adsorção de água.

O grau de compactação da área estudada apresentou valores semelhantes aos encontrados por Oliveira et al. (2010b) nas duas camadas (0-20 e 20-40 cm). Na camada de $20-40 \mathrm{~cm}$, o GC alcançou média de $88 \%$, valor acima daquele estipulado por Linstrom \& Voorhess (1994) como prejudicial ao desenvolvimento e rendimento das culturas (86\%). Oliveira et al. (2010b) verificaram que o manejo e o tráfego são os principais responsáveis pelo alto valor do GC. Segundo Silva \& Cabeda (2006) a capacidade de suporte do solo está correlacionada com um elevado grau de compactação ou uma boa estabilidade estrutural.

Selecionaram-se, com base na validação cruzada, os modelos de semivariogramas que melhor se ajustaram à distribuição das semivariâncias experimentais (Tabela 2) enquanto ao

Tabela 2. M odelos, parâmetros dos semivariogramas experimentais e validação cruzada para a variável densidade do solo (Ds), teor de água $\left(\mathrm{U} g\right.$ ), porosidade total $(\mathrm{Pt})$, limites de consistência (LL, LP, IP), densidade seca máxima ( $\left.\mathrm{DS}_{\max }\right)$, umidade crítica (U gcrit, grau de compactação (GC) e carbono orgânico (CO)

\begin{tabular}{|c|c|c|c|c|c|c|c|c|c|c|}
\hline Variáveis & Ds & Ug & $\mathrm{Pt}$ & LL & LP & $\mathbf{I P}$ & $D s_{\max }$ & Ugcrit & GC & $\mathrm{CO}$ \\
\hline $\begin{array}{l}{ }^{1} \mathrm{C}_{0} \\
{ }^{2} \mathrm{C}_{1} \\
{ }^{3} \mathrm{a} \\
\text { Modelo } \\
{ }^{7} \mathrm{GDE} \\
\text { Média } \\
\text { DP } \\
{ }^{8} \mathrm{R}^{2}\end{array}$ & $\begin{array}{c}1, \mathrm{E}-5 \\
1,08 \\
63,57 \\
{ }^{5} \operatorname{Exp} \\
9, \mathrm{E}-4 \\
-0,03 \\
0,94 \\
0,7 \\
\end{array}$ & $\begin{array}{c}0,19 \\
0,5 \\
27,79 \\
{ }^{6} \mathrm{Esf}^{\mathrm{RT}} \\
27,62 \\
0,02 \\
1,19 \\
0,68\end{array}$ & $\begin{array}{c}0,67 \\
0,16 \\
35,26 \\
\text { Esf } \\
80,51 \\
0,05 \\
1,08 \\
0,36\end{array}$ & $\begin{array}{c}0,34 \\
1,61 \\
147 \\
\text { Exp } \\
17,28 \\
0,023 \\
0,859 \\
0,58\end{array}$ & $\begin{array}{c}0-20 \mathrm{~cm} \\
{ }^{4} \mathrm{Epp}\end{array}$ & $\begin{array}{c}0,26 \\
1,31 \\
61,8 \\
\text { Exp } \\
16,48 \\
0,067 \\
0,753 \\
0,36\end{array}$ & $\begin{array}{c}8, \mathrm{E}-4 \\
1,12 \\
98,4 \\
\text { Esf } \\
0,07 \\
-0,008 \\
1,107 \\
0,8\end{array}$ & $\begin{array}{c}0,04 \\
0,34 \\
56,7 \\
E s f^{\text {th }} \\
11,11 \\
-0,001 \\
0,99 \\
0,81\end{array}$ & $\begin{array}{c}0,60 \\
1,06 \\
109,36 \\
\text { Esf } \\
36,32 \\
-0,02 \\
1,16 \\
0,93\end{array}$ & $\begin{array}{c}1, E-6 \\
1,14 \\
31,44 \\
\text { Esf }{ }^{\text {tt }} \\
1, \mathrm{E}-4 \\
-0,03 \\
1,3 \\
0,64\end{array}$ \\
\hline \multicolumn{11}{|c|}{$20-40 \mathrm{~cm}$} \\
\hline $\begin{array}{l}\mathrm{C}_{0} \\
\mathrm{C}_{1} \\
\mathrm{a} \\
\text { Modelo }\end{array}$ & $\begin{array}{c}0,55 \\
0,5 \\
55,72 \\
\text { Esf }\end{array}$ & $\begin{array}{c}0,13 \\
0,93 \\
53,43 \\
\text { Esf }\end{array}$ & $\begin{array}{c}0,09 \\
0,99 \\
62,19 \\
\text { Exp }\end{array}$ & $\begin{array}{c}4, E-5 \\
0,97 \\
39 \\
\text { Esf }\end{array}$ & $\begin{array}{c}8, E-7 \\
0,92 \\
30,04 \\
\text { Esf }\end{array}$ & $\begin{array}{c}0,41 \\
0,90 \\
38,26 \\
\text { Esf }\end{array}$ & $\begin{array}{c}2, \mathrm{E}-3 \\
8, \mathrm{E}-1 \\
37,6 \\
\text { Esf }\end{array}$ & $\begin{array}{c}0,16 \\
1,08 \\
89,34 \\
\operatorname{Exp}\end{array}$ & $\begin{array}{c}0,53 \\
1,09 \\
67,63 \\
\text { Esf }\end{array}$ & $\begin{array}{c}1, \mathrm{E}-5 \\
2,32 \\
28,32 \\
\mathrm{Esfft}^{\mathrm{t}}\end{array}$ \\
\hline $\begin{array}{l}\text { GDE } \\
\text { Média } \\
\text { DP } \\
\text { R }^{2}\end{array}$ & $\begin{array}{c}52,38 \\
-0,03 \\
1,05 \\
0,92\end{array}$ & $\begin{array}{c}12,2 \\
-0,03 \\
1,17 \\
0,64\end{array}$ & $\begin{array}{l}8,33 \\
0,06 \\
0,92 \\
0,77\end{array}$ & $\begin{array}{c}4, E-3 \\
-0,03 \\
1,24 \\
0,49\end{array}$ & $\begin{array}{c}8, E-5 \\
-0,03 \\
0,98 \\
0,45\end{array}$ & $\begin{array}{l}31,29 \\
0,02 \\
0,96 \\
0,73\end{array}$ & $\begin{array}{c}0,24 \\
0 \\
0,77 \\
0,53\end{array}$ & $\begin{array}{c}12,90 \\
0,01 \\
0,65 \\
0,78\end{array}$ & $\begin{array}{c}32,72 \\
-0,02 \\
1,08 \\
0,77\end{array}$ & $\begin{array}{c}4, E-4 \\
-0,06 \\
1,32 \\
0,14\end{array}$ \\
\hline
\end{tabular}

${ }^{1}$ Efeito pepita, ${ }^{2}$ patamar- $C_{0},{ }^{3}$ alcance, ${ }^{4}$ efeito pepita puro, ${ }^{5}$ exponencial, ${ }^{6}$ esférico, ${ }^{7}$ grau de dependência es pacial $=\left[C_{0} /\left(C_{0}+C_{1}\right)\right] \times 100,{ }^{8}$ coeficiente de determinação, ${ }^{\text {th }}-$ retirada a tendência 
modelo exponencial se ajustaram as variáveis Ds, LL, IP, na camada $0-20 \mathrm{~cm}$ e Pt, Ugcrit, na camada $20-40 \mathrm{~cm}$. As demais variáveis se ajustaram melhor ao modelo esférico. Os semivariogramas escalonados podem ser observados nas Figuras 1 e 2 que apresentam estacionaridade de segunda ordem para as variáveis analisadas (patamar claro e bem definido).

O grau de dependência espacial (GDE) evidenciou que existe de média (entre 25 e $75 \%$ ) a forte $(<25 \%)$ dependência para a maioria das variáveis (Tabela 2) indicando que tais variáveis não são aleatórias no espaço. Segundo Cambardella et al. (1994) variáveis que apresentam forte grau de dependência são mais influenciadas por propriedades intrínsecas do solo e a porosidade na camada $0-20 \mathrm{~cm}$ foi a única a apresentar fraca dependência.

O LP na camada 0-20 cm (Figura 1E) apresentou efeito pepita puro, que é a ausência de dependência espacial, em razão da

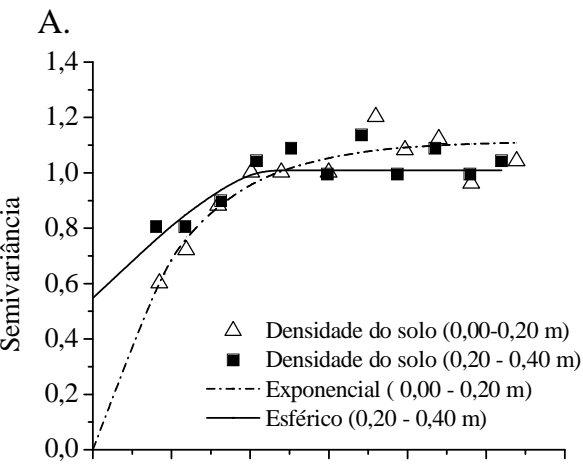

D.

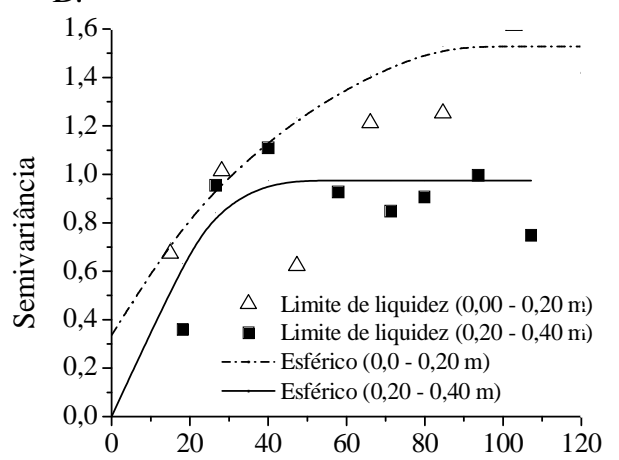

B.

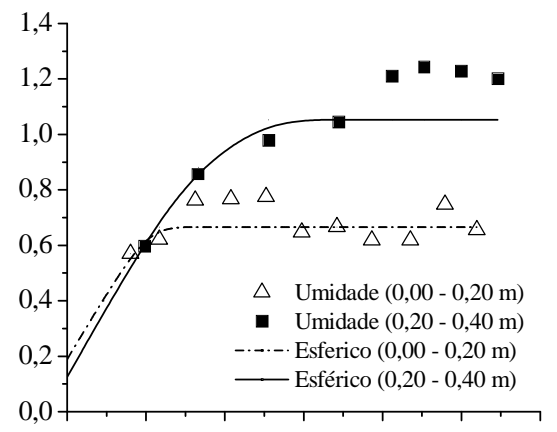

$\mathrm{E}$

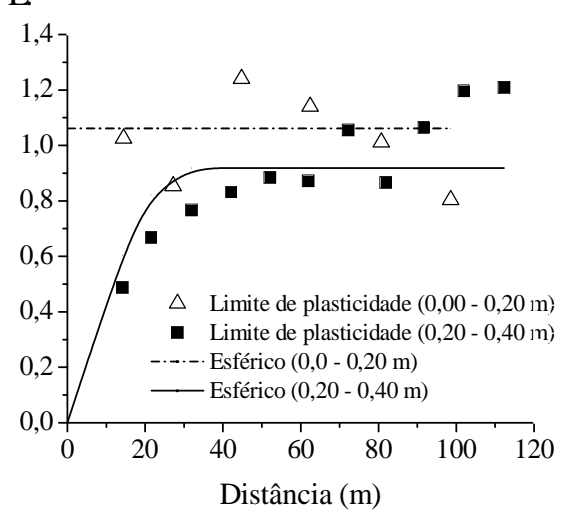

C.

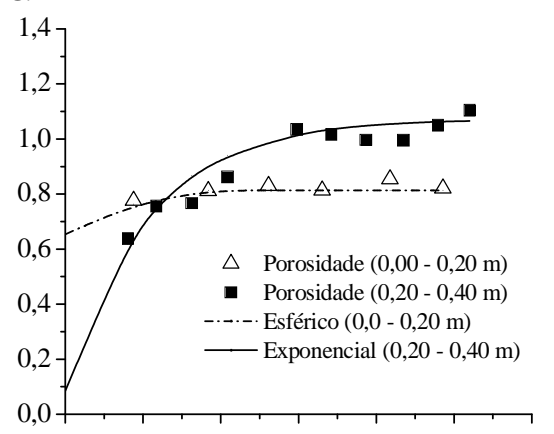

$\mathrm{F}$.

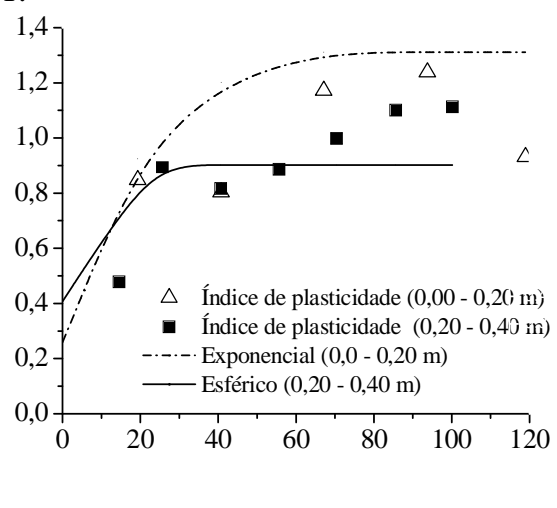

Figura 1. Semivariogramas dos parâmetros: densidade (A), umidade (B), porosidade (C), Limite de liquidez (D), limite de plasticidade (E) e índice de plasticidade (F)

A.

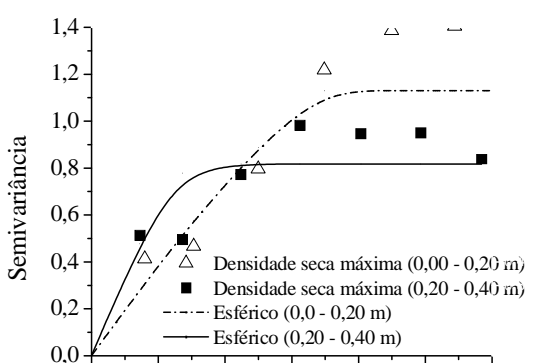

C.

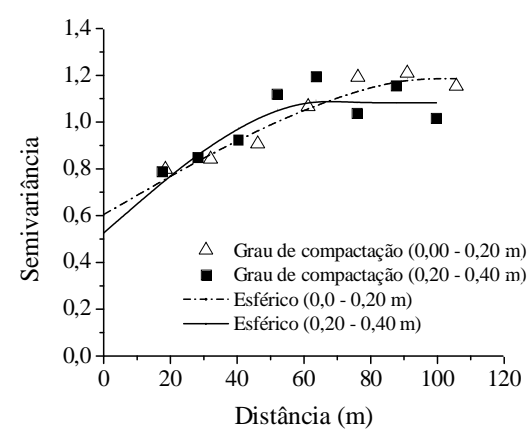

B.

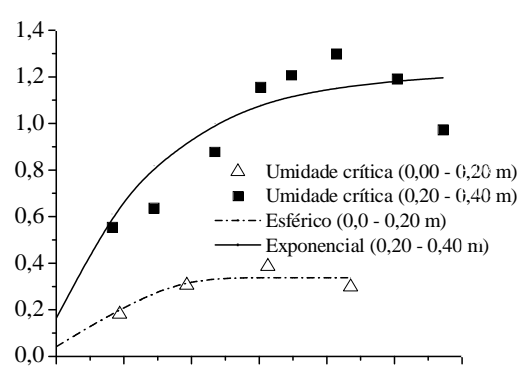

D.

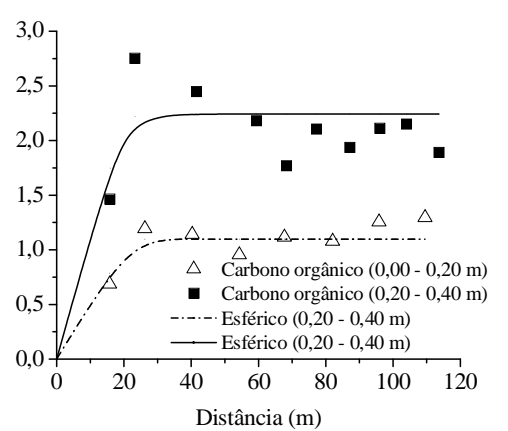

Figura 2. Semivariogramas densidade seca máxima (D S $\max )(A)$, umidade crítica (U gc) (B), grau de compactação $(G C)$ (C) e carbono orgânico (CO) (D) 
A.

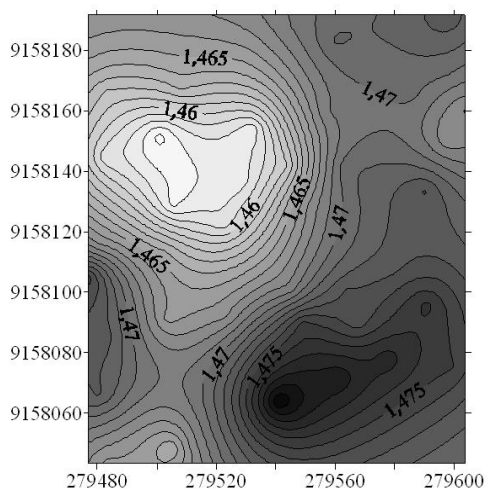

D.

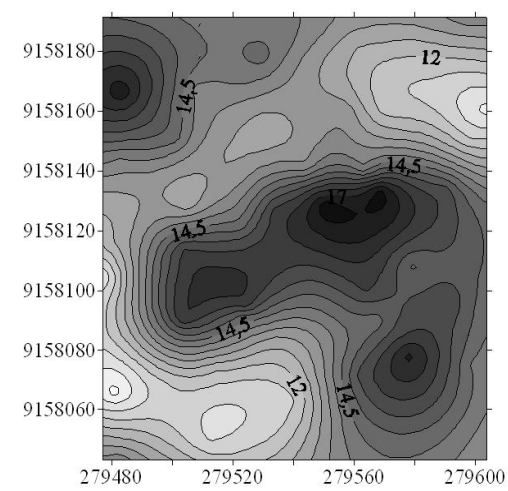

B.

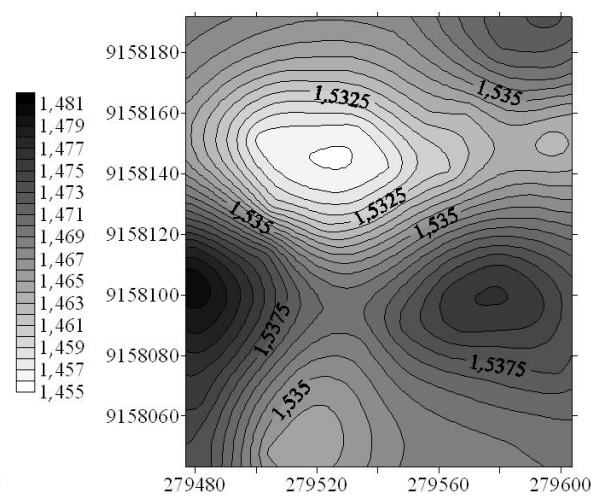

E.

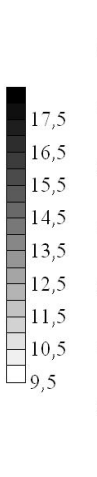

C.
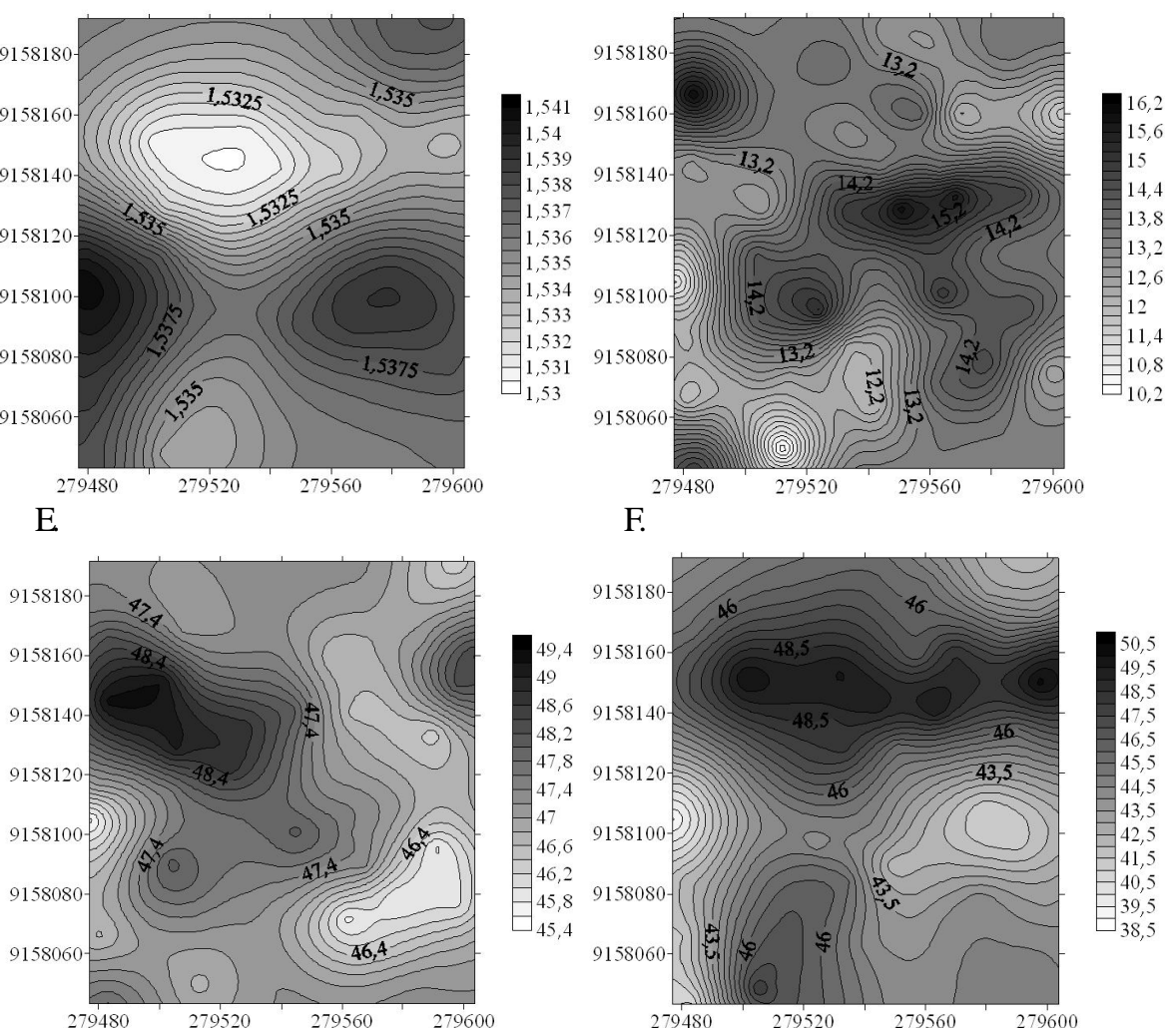

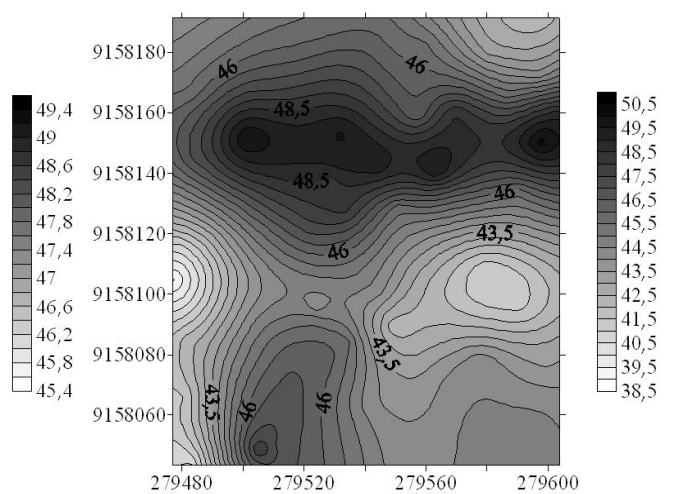

Figura 3. Mapas dos atributos densidade do solo $(A)(0-20 \mathrm{~cm})$ e $(B)(20-40 \mathrm{~cm})$; umidade $(C)(0-20 \mathrm{~cm})$ e (D) (20-40 $\mathrm{cm})$ e porosidade $(\mathrm{E})(0-20 \mathrm{~cm})$ e $(\mathrm{F})(20-40 \mathrm{~cm})$

Tabela 3. Matriz de correlação linear entre os atributos do solo e o carbono orgânico

\begin{tabular}{|c|c|c|c|c|c|c|c|c|c|c|}
\hline & Ds & Ug & Pt & LL & LP & $\mathbf{I P}$ & Dsmax & Ugcrit & GC & $\mathrm{CO}$ \\
\hline $\begin{array}{l}\text { Ds } \\
\text { Ug } \\
\text { Pt } \\
\text { LL } \\
\text { LP } \\
\text { IP } \\
\text { Dsmax } \\
\text { Ugcrit } \\
\text { GC } \\
\text { CO }\end{array}$ & 1,00 & $\begin{array}{l}0,23 \\
1,00\end{array}$ & $\begin{array}{c}-0,99 * \\
-0,22 \\
1,00\end{array}$ & $\begin{array}{c}-0,32 \\
-0,12 \\
0,34 \\
1,00\end{array}$ & $\begin{array}{c}0-20 \mathrm{~cm} \\
0,08 \\
-0,13 \\
-0,06 \\
0,50 * \\
1,00\end{array}$ & $\begin{array}{c}-0,42^{*} \\
-0,06 \\
0,44^{*} \\
0,85^{*} \\
-0,03 \\
1,00\end{array}$ & $\begin{array}{c}0,14 \\
-0,26 \\
-0,13 \\
0,24 \\
0,09 \\
0,22 \\
1,00\end{array}$ & $\begin{array}{c}-0,38 \\
0,21 \\
0,41 \\
0,49^{*} \\
0,11 \\
0,50^{*} \\
-0,36 \\
1,00\end{array}$ & $\begin{array}{c}0,98^{*} \\
0,28 \\
-0,97^{*} \\
-0,38 \\
0,06 \\
-0,48^{*} \\
-0,07 \\
-0,31 \\
1,00\end{array}$ & $\begin{array}{c}0,16 \\
0,04 \\
-0,18 \\
-0,49 * \\
-0,10 \\
-0,51^{*} \\
-0,33 \\
-0,44^{*} \\
0,23 \\
1,00\end{array}$ \\
\hline \multicolumn{11}{|c|}{$20-40 \mathrm{~cm}$} \\
\hline Ds & 1,00 & 0,05 & $-0,98 *$ & $-0,04$ & $-0,40^{*}$ & 0,29 & $-0,25$ & 0,11 & $0,98^{*}$ & $-0,14$ \\
\hline Ug & & 1,00 & $-0,07$ & 0,15 & $0,44^{*}$ & $-0,24$ & $-0,52^{*}$ & $0,57 *$ & 0,16 & 0,22 \\
\hline Pt & & & 1,00 & $-0,06$ & $0,37 *$ & $-0,33$ & 0,25 & $-0,14$ & $-0,95^{*}$ & 0,17 \\
\hline LL & & & & 1,00 & 0,08 & $0,63^{*}$ & 0,08 & 0,01 & $-0,05$ & $-0,06$ \\
\hline LP & & & & & 1,00 & $-0,73^{*}$ & 0,19 & 0,01 & $-0,41 *$ & 0,09 \\
\hline IP & & & & & & 1,00 & $-0,09$ & 0,00 & 0,29 & $-0,11$ \\
\hline Dsmax & & & & & & & 1,00 & $-0,91^{*}$ & $-0,46^{*}$ & $-0,23$ \\
\hline Ugcrit & & & & & & & & 1,00 & 0,31 & 0,24 \\
\hline $\mathrm{GC}$ & & & & & & & & & 1,00 & $-0,07$ \\
\hline $\mathrm{CO}$ & & & & & & & & & & 1,00 \\
\hline
\end{tabular}

impossibilidade de se ajustar um modelo de semivariograma para tais variáveis, na escala de separação adotada entre pontos de amostragem. O efeito pepita puro pode estar relacionado a um erro analítico ou a variações não detectadas, com base na distância de amostragem utilizada no grid (Cambardella et al., 1994). Dentre as prováveis causas para tal comportamento, o uso intensivo do solo pode causar alterações na estrutura de dependência espacial ocasionando a aleatoriedade de variáveis físicas. A investigação mais aprofundada das escalas de dependência poderia ser efetuada adotando-se subgrids no interior do grid original, de modo a estimar semivariâncias para distâncias de separação inferiores a 20 m; entretanto, tal análise 
A.

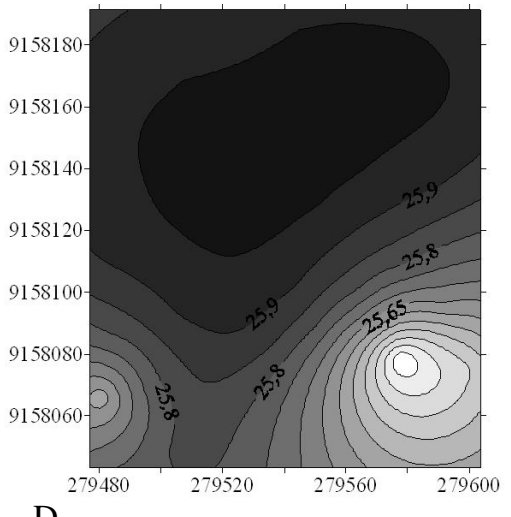

D.

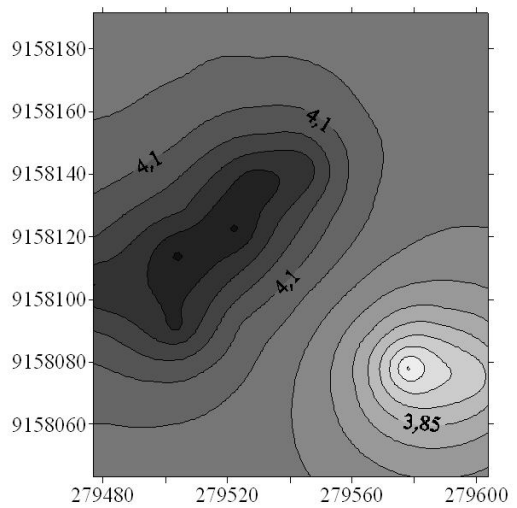

B.

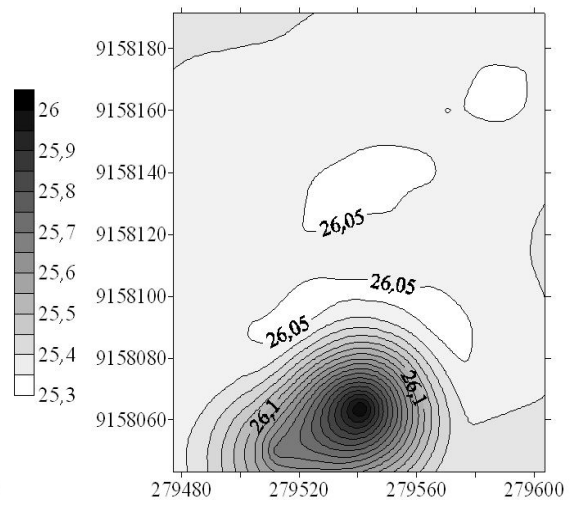

$\mathrm{E}$

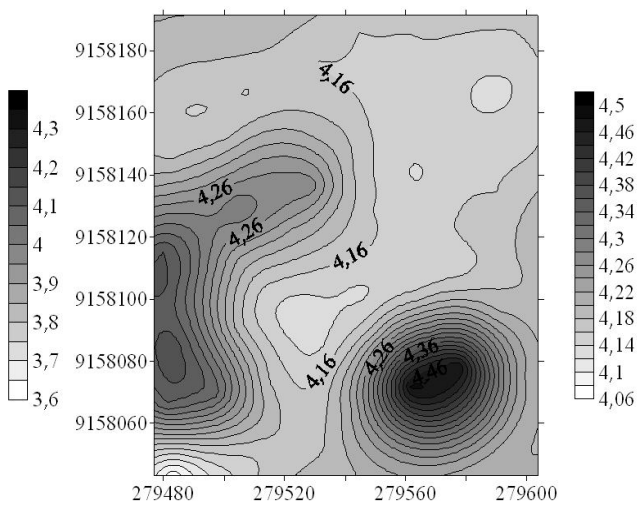

C.

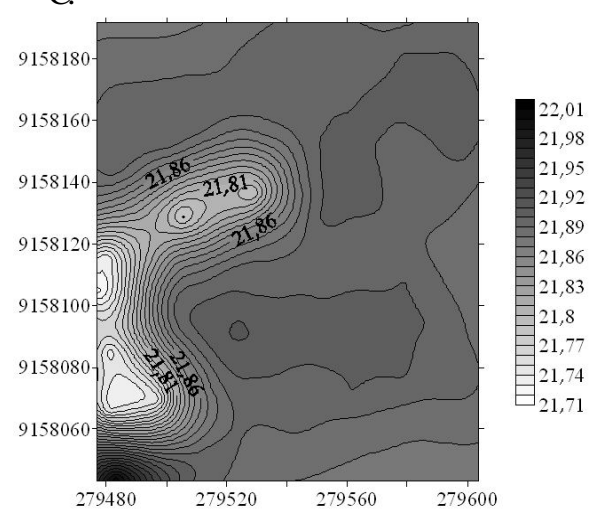

Figura 4. Mapas limite de liquidez (A) $(0-20 \mathrm{~cm})$ e (B) $(20-40 \mathrm{~cm})$; limite de plasticidade (C) $20-40 \mathrm{~cm}$ e índice de plasticidade (D) $(0-20 \mathrm{~cm})$ e $(\mathrm{E})(20-40 \mathrm{~cm})$

A.

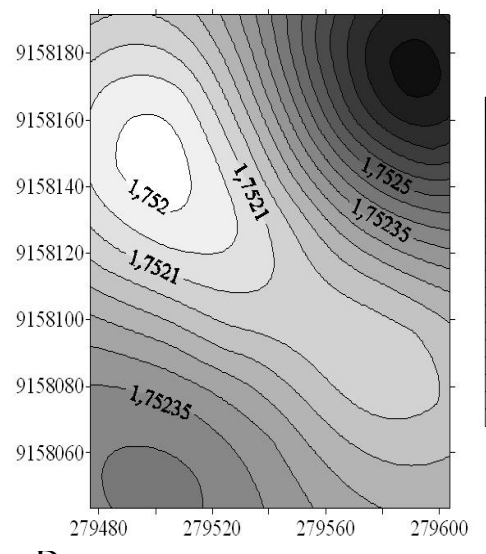

D.

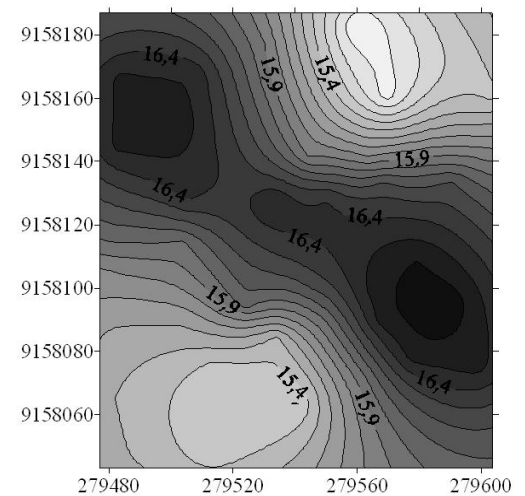

B.

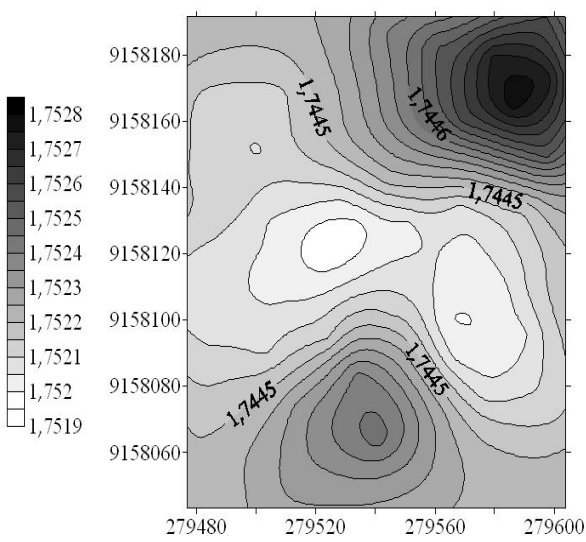

$\mathrm{E}$

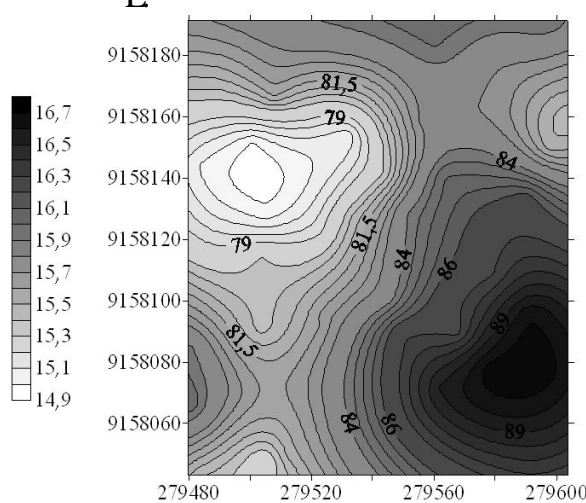

C.

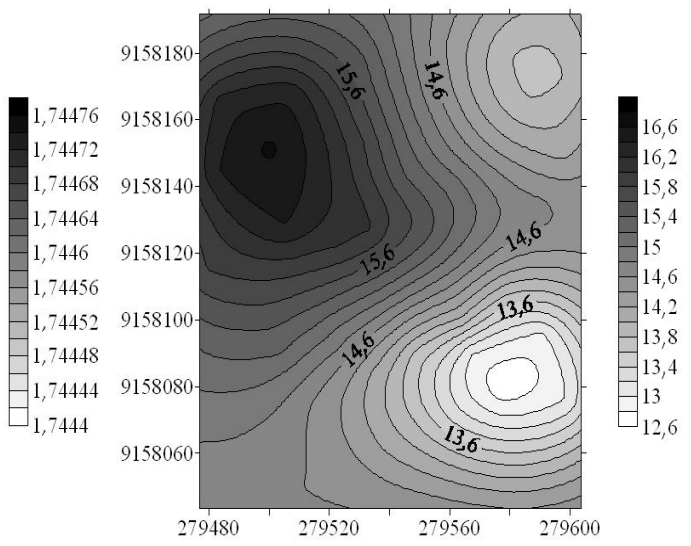

F.

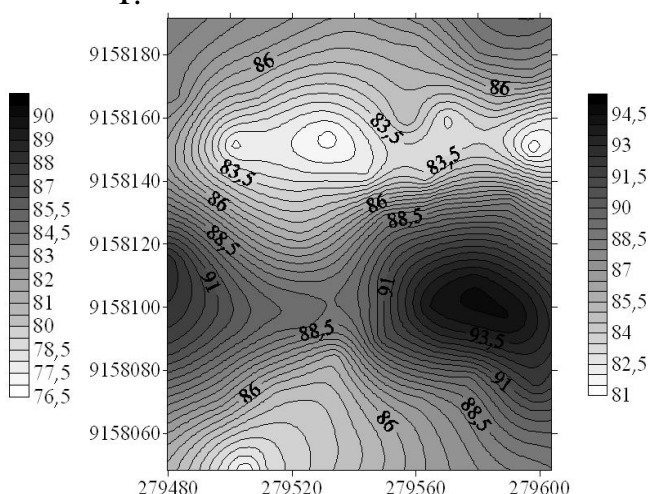

Figura 5. Mapas da densidade seca máxima (A) $(0-20 \mathrm{~cm})$ e (B) $(20-40 \mathrm{~cm})$; umidade crítica (C) $(0-20 \mathrm{~cm})$ e (D) (20-40 $\mathrm{cm})$ e grau de compactação (E) $(0-20 \mathrm{~cm})$ e $(\mathrm{F})(20-40 \mathrm{~cm})$ 
A.

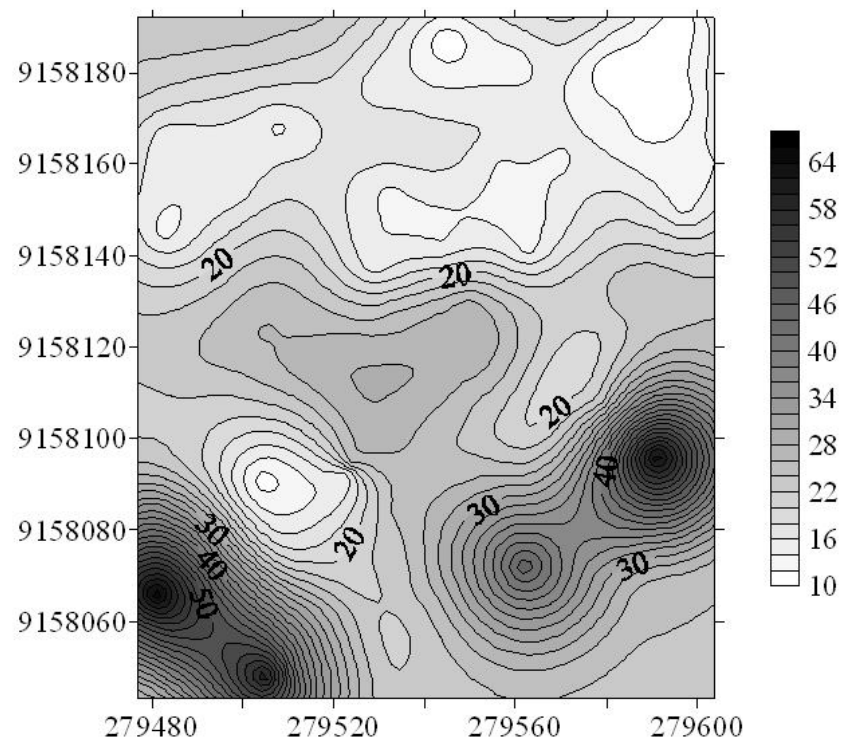

Figura 6. Mapas carbono orgânico (A) $0-20 \mathrm{~cm}$ e (B)
B.

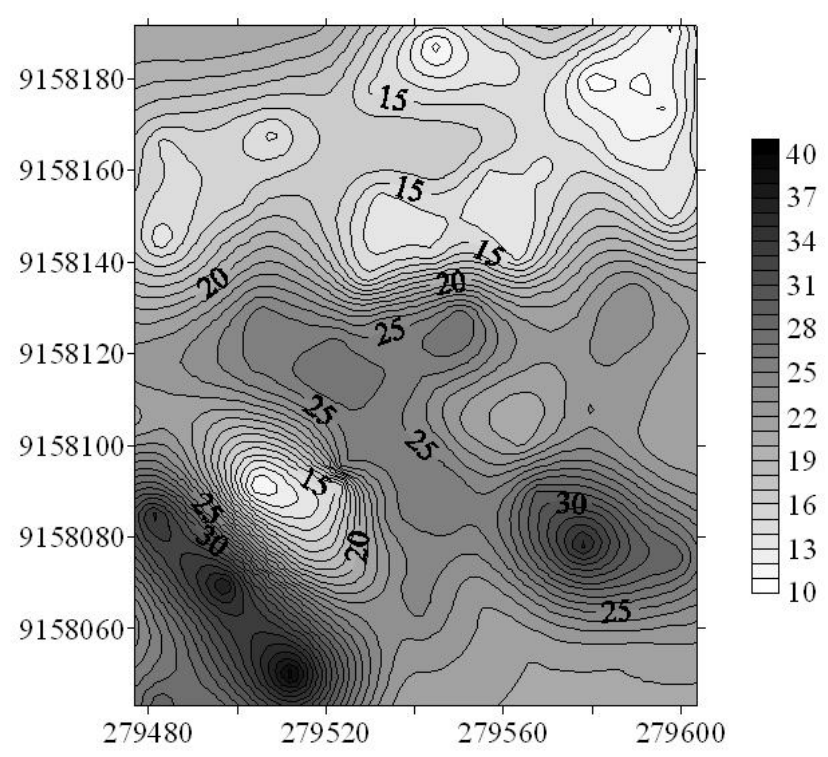

complementar estava fora do escopo deste estudo, não tendo sido conduzida.

Verificou-se que a umidade crítica obtida do ensaio de Proctor normal foi maior na camada de $20-40 \mathrm{~cm}$ devido à diminuiç̧ão do teor de areia e ao aumento do teor de argila na camada $20-40 \mathrm{~cm}$, pois os solos arenosos necessitam de menor quantidade de água para alcançar a densidade máxima enquanto solos com maior teor de argila requerem mais água para o mesmo fim.

A maior concentração de $\mathrm{CO}$ na superfície do solo pode ter ocasionado um amortecimento do efeito das cargas aplicadas ao solo, observado no ensaio de Proctor normal, confirmado por Silva et al. (2011), assim como Braida et al. (2006), que citam que o acúmulo de $\mathrm{CO}$ proporcionado por diferentes sistemas de manejo reduz a $\mathrm{Ds}_{\max }$ quando o solo é submetido à compactação, concorrendo com as partículas minerais pela umidade e seu efeito é mais intenso em partículas de areia, sendo a matéria orgânica capaz de reduzir o efeito lubrificante da água sobre as partículas, fato que pode ser verificado pela correlação negativa entre $\mathrm{CO}$ e $\mathrm{Ds}_{\max }$, nas duas camadas, $\mathrm{r}^{2}=-0,33 \mathrm{e}-0,23$ (Tabela 3) para as camadas $0-20$ e $20-40 \mathrm{~cm}$, respectivamente. A relação entre $\mathrm{CO}$ e $\mathrm{Ds}_{\max }$ pode ser visualizada nas camadas de $0-20$ e $20-40 \mathrm{~cm}$, Figuras $6 \mathrm{~A}$ e B e 4Ae B.

A Ds (Figura 3A e B) apresentou correlação negativa com a porosidade total (Figura 3E e F) e positiva com o grau de compactação (Figuras 5E e F); obtiveram-se, pela correlação simples realizada, valores acima de $\mathrm{r}^{2}=0,97$ para as variáveis (Tabela 3).

A correlação entre as variáveis $\mathrm{CO}$ e os limites de consistência apresentou relação negativa entre si na superfície, com $\mathrm{r}^{2} \mathrm{de}-0,49,-0,10$ (Tabela 3) para correlação entre CO e LL, LP (Figuras 6A e 4A); na camada $20-40 \mathrm{~cm}$ a relação entre as variáveis, apesar de negativas, não foram significativas, com $\mathrm{r}^{2}$ $<0,11$ (Tabela 3). Rolim \& Freire (1997) encontraram, ao estudar os índices de consistência de solos arenosos e argilosos com doses crescentes de vinhaça, comportamento semelhante para LL e LP, sendo que todos os tratamentos com vinhaça concentrada reduziram os valores dos limites de liquidez e plasticidade em relação à testemunha, pela observação das médias dos ensaios; a menor correlação encontrada na camada 20-40 cm é devida, provavelmente, ao menor teor de carbono orgânico e à sua menor influência nas propriedades do solo.

A Ugcrit apresentou relação negativa com a $\mathrm{Ds}_{\max }$ (Figuras $5 \mathrm{~A}, \mathrm{~B}, \mathrm{C} \mathrm{e} \mathrm{D),} \mathrm{com} \mathrm{r}^{2}=-0,36 \mathrm{e}-0,91^{*}$, para a camada $0-20 \mathrm{~cm}$ e 20-40 cm, respectivamente (Tabela 3 ).

\section{CONCLUSÕES}

1. As variáveis densidade do solo (Ds), umidade (Ug) e porosidade $(\mathrm{Pt})$ para a área estudada, apresentaram elevadas correlações com os limites de consistência, grau de compactação e densidade seca máxima do solo enquanto o carbono orgânico apresentou melhor correlação com os limites de consistência e umidade crítica do solo.

2. O valor médio do grau de compactação na camada $20-40$ $\mathrm{cm}$ indicou que a compactação da área pode ser prejudicial ao desenvolvimento e rendimento da cultura.

3. Pelos limites de consistência o solo pode apresentar alta contração exigindo cuidado, em ambos os perfis.

4. O carbono orgânico contribuiu para a redução da densidade seca máxima, observada no ensaio de Proctor normal.

\section{LITERATURA CITADA}

Bebé,F. V.; Rolim, M. M.; Pedrosa, M.E. R.; Silva, G B.; Oliveira, V. S. Avaliação de solos sob diferentes períodos de aplicação com vinhaça. Revista Brasileira de Engenharia Agrícola e Ambiental, v.13, p.781-787, 2009.

Braida, J. A.; Reichert, J. M.; Reinert, D. J.; Veiga, M. Teor de carbono orgânico e a susceptibilidade à compactação de um Nitossolo e um Argissolo. Revista Brasileira de Engenharia Agrícola e Ambiental, v.14, p.131-139, 2010. 
Braida. J. A.; Reichert, J. M.; Veiga, M.; Reinert, D. J. Resíduos vegetais na superfície e carbono orgânico do solo e suas relações com a densidade máxima obtida no ensaio de Proctor. Revista Brasileira de Ciência do Solo, v.30, p.605614, 2006.

Bonini, A. K.; Secco, D.; Santos, R. F.; Reinert, D. J.; Reichert, J. M. Atributos físico-hidricos e produtividade de trigo em um Latossolo sob estados de compactação. Ciência Rural, v.41, p.1543-1548, 2011.

Cambardella, C. A.; Moorman, J. M.; Novak, T. B.; Karlen, D. L.; Turco, R. F.; Konopka, A. E.Field-scale variability of soil properties in Central Iowa Soils. Soil Science Society of America Journal, v.58, p.1501-1511, 1994.

CONAB - Companhia Nacional de Abastecimento. Acompanhamento de safra brasileira: Cana-de-açúcar, primeiro levantamento, abril/2012. Brasília: CONAB, 2012. $19 \mathrm{p}$.

Dias Junior, M. S.; Pierce, F. J. O processo de compactação do solo e sua modelagem. Revisão de Literatura. Revista Brasileira de Ciência do Solo, v.20, p.175-182, 1996.

EMBRAPA - Empresa Brasileira de Pesquisa Agropecuária. Manual de métodos de análises de solo. 2.ed. Rio de Janeiro: Ministério da Agricultura e do Abastecimento, 1997. 212p.

Englund, E.; Sparks, A. GeoEAS (Geostatistical Environmental Assessment Software) Las Vegas: U. S. Environmental Protection Agency, 1991. EPA/600/4-88/033a.

Farias, C. H. de A.; Fernandes, P. D.; Gheyi, H. R.; Dantas Neto, J. Qualidade industrial de cana-de-açúcar sob irrigação e adubação com zinco, em Tabuleiro Costeiro paraibano. Revista Brasileira de Engenharia Agrícola e Ambiental, v.13, p.419-428, 2009.

Figueiredo, L. H. A.; Dias Júnior, M. S.; Ferreira, M. M. Umidade crítica de compactação e densidade do solo máxima em resposta a sistemas de manejo num Latossolo Roxo. Revista Brasileira de Ciência do Solo, v.24, p.487-493, 2000.

Golden Software. Surfer 7.0 - user's guide. New York: Golden Software, 1999. 619p.

Guimarães, R. M. L.; Gonçalves, A. C. A.; Tormena, C. A.; Folegatti, M. V.; Blainsk, E. Variabilidade espacial de propriedades físicohídricas de um Nitossolo sob a cultura do feijoeiro irrigado. Engenharia Agrícola, v.30, p.657-669, 2010.

Hoaglin, D. C.; Mosteller, F.; Tukey, J. W. Análise exploratória de dados: técnicas robustas, um guia. Lisboa: Salamandra, 1992. 446p.

Klein, V. A. Densidade relativa - Um indicador da qualidade física de um Latossolo Vermelho. Revista Ciência Agronômica, v.5, p.26-32, 2006.

Kondo, M. K.; Dias Júnior, M. S. Compressibilidade de três Latossolos em função da umidade e uso. Revista Brasiliera de Ciência do Solo, v.23, p.211-218, 1999.

Lindstrom, M. J.; Voorhees, W. B. Response of temperate crops in North America to soil compaction. In: Soane, B. D.; Ouwerkerk, C. van (eds.). Soil compaction in crop production. London: Elsevier, Cap.12, p.265-286. 1994.
Miranda, E. E. V.; Lanças, K. P.; Silva, R. B. Modelagem e mapas da capacidade suporte de carga de um Latossolo Vermelho cultivado com cana-de-açúcar. Energia na Agricultura, v.22, p.42-54, 2007.

Oliveira, V. S.; Rolim, M. M.; Vasconcelos, R. F. B.; Costa, Y. D. J.; Pedrosa, E. M. R. Compactação de um Argissolo Amarelo distrocoeso submetido a diferentes manejos. Revista Brasileira de Engenharia Agrícola e Ambiental, v.14, p. 914920, 2010a.

Oliveira, V. S.; Rolim, M. M.; Vasconcelos, R. F. B.; Pedrosa, E. M. R. Distribuição de agregados e carbono orgânico em um Argissolo Amarelo distrocoeso em diferentes manejos. Revista Brasileira de Engenharia Agrícola e Ambiental, v.14, p.907-913, 2010b.

Rolim, M. M.; Freire, W. J. Efeito da vinhaça concentrada sobre a estabilidade estrutural dos agregados do solo. Engenharia Agrícola, v.16, p.69-76, 1997.

Severiano, E. C.; Oliveira, G. C.; Dias Júnior, M. S.; Castro, M. B.; Oliveira, L. F. C.; Costa, K. A. P. Compactação de solos cultivados com cana-de-açúcar: II -quantificação das restrições às funções edáficas do solo em decorrência da compactação prejudicial. Engenharia Agrícola, v.30, p.404$413,2010$.

Silva, A. J. N.; Cabeda, M. S. V. Modificações na matriz de um Argissolo Amarelo coeso sob diferentes sistemas de manejo com cana-de-açúcar. Revista Brasileira de Engenharia Agrícola e Ambiental, v.10, p.554-562, 2006.

Silva, A. J. N; Cabeda, M. S. V.; Carvalho, F. G. Matéria orgânica e propriedades físicas de um Argissolo Amarelo coeso sob sistemas de manejo com cana-de-açúcar. Revista Brasileira de Engenharia Agrícola e Ambiental, v.10, p.579$585,2006 b$.

Silva, A. R.; Dias Junior, M. S.; Guimarães, T. G.; Araujo Junior, C. F. Modelagem da capacidade de suporte de carga e quantificação dos efeitos das operações mecanizadas em um Latossolo Amarelo cultivado com cafeeiros. Revista Brasileira de Ciência do Solo, v.30, p.207-216, 2006a.

Silva, D. A.; Souza, L. C. F.; Vitorino, A. C. T.; Gonçalves, M. C. Aporte de fitomassa pelas sucessões de culturas e sua influência em atributos físicos do solo no sistema plantio direto. Bragantia, v.70, p.147-156, 2011.

Siqueira, G. M.; Vieira, S. R.; Ceddia, M. B. Variabilidade de atributos físicos do solo determinados por métodos diversos. Bragantia, v.67, p.203-211, 2008.

StatSoft - Statistica (Data Analysis Software System), versão 7.0, (www.statsoft.com), 2004.

Vasconcelos, R. F. B.; Cantalice, J. R. B.; Silva, A. J. N.; Oliveira, V. S.; Silva, Y. A. B. Limites de consistência e propriedades químicas de um Latossolo amarelo distrocoeso sob aplicação de diferentes resíduos da cana-de-açúcar. Revista Brasileira de Ciência do Solo, v.34, p.639-648, 2010.

Warrick, A. W.; Nielsen, D. R. Spatial variability of soil physical properties in the field. In: Hillel, D. (ed.). Application of soil physics, New York: Academic Press, 1980. p.319-324. 